\title{
ENHANCEMENT OF SILICON USING MICRO-PATTERNED SURFACES OF THIN FILMS
}

\author{
Emilia Kaivosoja ${ }^{1,2, \#, ~ S a m i ~ M y l l y m a a ~}{ }^{3, \#, ~ V e s a-P e t t e r i ~ K o u r i ~}{ }^{1,2}$, Katja Myllymaa $^{3,4}$, Reijo Lappalainen³, Yrjö T. \\ Konttinen ${ }^{1,5,6 *}$
}

\begin{abstract}
${ }^{1}$ Department of Medicine, Institute of Clinical Medicine, Helsinki University Central Hospital, ${ }^{2}$ Department of Anatomy, Institute of Biomedicine, University of Helsinki, ${ }^{3}$ Department of Physics, University of Kuopio, ${ }^{4}$ Microsensor Laboratory, School of Engineering and Technology, Savonia University of Applied Sciences, ${ }^{5}$ ORTON Orthopaedic Hospital of the Invalid Foundation, ${ }^{6} \mathrm{COXA}$ Hospital for Joint Replacement Tampere, Finland \#These authors contributed equally to the paper
\end{abstract}

\begin{abstract}
Micro-textured biomaterials might enhance cytocompatibility of silicon-based micro-electromechanical system (bio-MEMS) dummies. Photolithography-physical vapour deposition was used to produce diamond-like carbon (DLC) or Ti squares and circles on silicon, and also their inverse replicas; then DLC and Ti were compared for their guiding potential, using a SaOS-2 cell model. Scanning electron microscopy at 48 hours indicated cells were well-spread on large-sized patterns (several cells on one pattern) and assumed the geometrical architecture of underlying features. Mediumsized patterns (slightly smaller than solitary indicator cells) were inhabited by singular cells, which stretched from one island to another, assuming longitudinal or branching morphologies. On small-sized patterns (much smaller than individual cells) cells covered large micro-textured areas, but cellular filopodia bypassed the bare silicon. Immunofluorescence and confocal laser scanning microscopy indicated that the actin cytoskeleton and vinculin-containing adhesion junctions were present on the patterned areas, but not on the bare silicon. Cell density/ coverage disclosed a 3.4-3.7-fold preference for the biomaterial patterns over silicon substrate $(p<0.001)$. Differences in the cellular response between materials were lost at 120 hours when cells were confluent. The working hypothesis was proven; enhancement by micro-patterning depends on the pattern size, shape and material and can be used to improve biocompatibility during the initial integration phase of the device.
\end{abstract}

Keywords: Biocompatibility, surface modification, micropatterning, photolithography, osteoblast.

*Address for correspondence:

Y.T. Konttinen

Department of Medicine

Institute of Clinical Medicine

Helsinki University Central Hospital

Haartmaninkatu 8, FI-00029 HUS, Finland

Telephone Number: +358-9-19125210

FAX Number: +358-9-191 25218

E-mail: yrjo.konttinen@helsinki.fi

\section{Introduction}

The ability to influence the adhesion and distribution of cells on a material is an important consideration in the development of new implantable biomaterials and biosensor devices. The physical and chemical properties of a material control which molecules are bound and at what concentrations, their ratios and the orientation of adsorption on the surface (Boyan et al., 1996; Healy et al., 1996; Keselowsky et al., 2003). In addition, surface topography at the nano- and microscales influences several aspects of cell behaviour (reviewed by Flemming et al., 1999). Surface patterning can be produced with photolithography or soft lithography (reviewed by Falconnet et al., 2006). Spatially organized surface microtextures allow studies on the effect of different surface cues on cell adhesion (Flemming et al., 1999), proliferation (van Kooten et al., 1998), survival (Chen et al., 1997) and function (Thomas et al., 2002), in short, on implant and device cyto- and biocompatibility.

One promising application of cell-substrate interactions relates to micro-patterned surfaces in microelectro-mechanical systems (MEMS), envisaged to be used as, for example, micron-scale pressure sensors and drug delivery systems (Grayson et al., 2004). A property inherent to MEMS is that they often require a silicon (Si) substrate as a platform into which sensors and electronics are integrated. Silicon, used extensively in electronics, is not per se a biocompatible material, and a poor substrate for cell adhesion and even slightly cytotoxic. These properties of silicon could limit the integration of siliconbased smart implants into the human body, and MEMS in biological systems (bioMEMS) (Voskerician et al., 2003). Total coating with biocompatible materials would bypass this problem; however, this is not feasible without losing a degree of functionality in MEMS. We hypothesise that partial surface modification of such artificial MEMS, with biocompatible materials and micro-texture design, could enhance their cytocompatibility. A thin cytocompatible layer will improve the biocompatibility of these devices. To meet this need, micro-patterned surfaces of thin films produced with photolithography combined with physical vapour deposition are an attractive approach because both the patterning and the thickness of the coating can easily be controlled. In addition, these methods could also contribute to improved adhesion and integration of cells in various tissue engineering applications. While some earlier pioneering studies in this field have focused on polymeric materials (Hanein et al., 2001; Owen et al., 

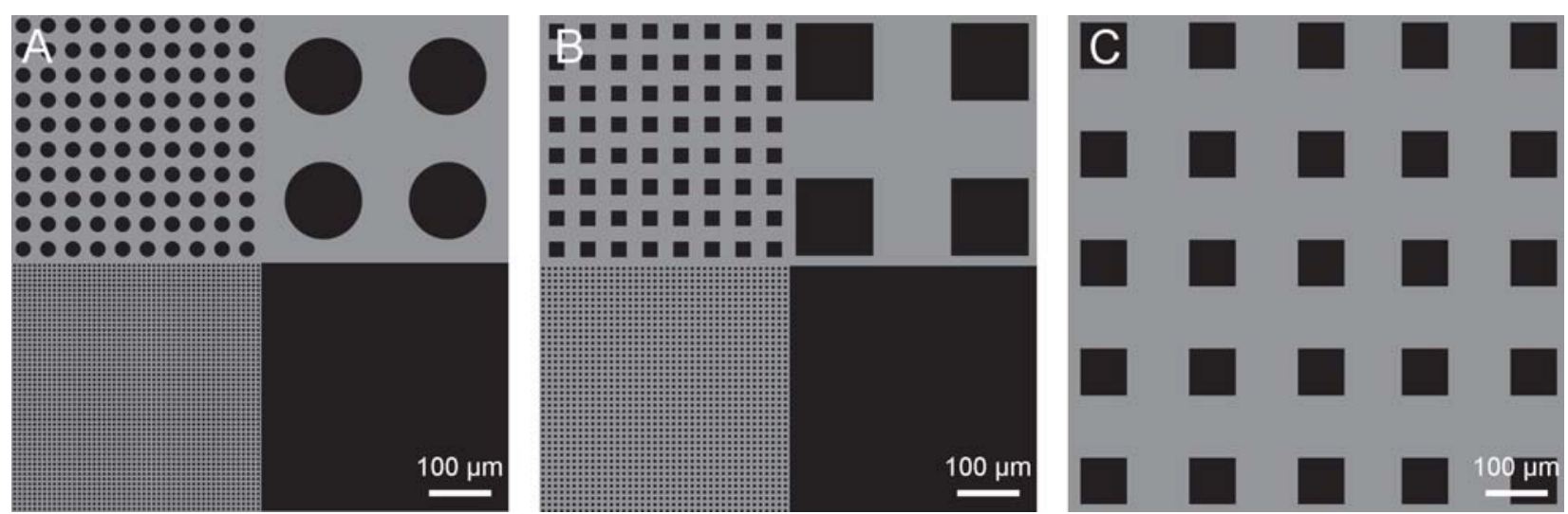

Fig.1. A schema presenting the sample types $(800 \mu \mathrm{m}$ x $800 \mu \mathrm{m}$ area from the middle of the samples). In panels A and $\mathrm{B}$, dark areas present titanium or DLC patterns on a silicon background or alternatively on inverse sample type silicon patterns on a titanium or DLC background. In panel C, dark areas present titanium or DLC patterns on a silicon background.

2005; Biggs et al., 2007a; Biggs et al., 2007b; Hart et al., 2007; Kunzler et al., 2007), with only one study conducted on metallic materials patterned on a silicon background (Berry et al., 2007). Some other cell types have also been evaluated, in particular on gold-silicon textured surfaces (Lan et al., 2005; Veiseh et al., 2004). Further to this, only neuroblastoma cells have previously been investigated on diamond like carbon (DLC)-silicon micro-textured surfaces (Kelly et al., 2008).

The aim of this study was to extend these earlier results to thin DLC and metallic (titanium) micro-textured films of different shapes and sizes applied on a silicon background. Here we used human SaOS-2 osteosarcoma cells to evaluate the effects of these patterned films on device cytocompatibility. DLC is a promising coating material with some useful physical and chemical properties, such as low friction, high resistance to corrosion and biocompatibility (Lappalainen et al., 1998; Santavirta et al., 1999) while the metals utilised in this study are commonly found as alloys in metallic implants.

\section{Materials and Methods}

\section{Sample fabrication}

Micro-patterned surfaces were fabricated on 4-inchdiameter and 0.5-mm-thick $<100>$ silicon wafers (Okmetic Ltd., Vantaa, Finland) by ultraviolet lithography and physical vapour deposition methods. Photomasks were designed by CleWin layout software (WieWeb software, Hengelo, The Netherlands) and fabricated on 4-inch glass plates with a structured chrome layer (Mikcell Oy, Ii, Finland).

The size of each final sample used in the cytocompatibility testing was $10 \mathrm{~mm} \times 10 \mathrm{~mm}$, containing four $4 \mathrm{~mm} \times 4 \mathrm{~mm}$ sample areas. In the first sample set, three of these areas contained squares (sides 5, 25 or 125 $\mu \mathrm{m})$ or circles (diameters 5, 25 or $125 \mu \mathrm{m}$ ) composed of either DLC or titanium on a silicon substrate, with the fourth sample area containing titanium or DLC as a homogeneous surface layer (Fig. 1, panels A and B). Regardless of the size of the patterns, circles covered $30.6 \%$ and squares $25 \%$ of the total sample surface area. In the second set of samples, the pattern and background material were reversed ("inverse samples") so that the patterns were composed of uncoated silicon squares or circles on a DLC or titanium background. Finally, the third set of samples contained regularly spaced $75 \mu \mathrm{m} \times 75 \mu \mathrm{m}$ squares covered with DLC or titanium with the distance between the squares being $100 \mu \mathrm{m}$ so that the patterns coated $18.4 \%$ of the total sample surface area (Fig. 1, panel C). The methods used for the preparation of these samples are described below.

\section{Ultraviolet lithography}

The silicon wafers were cleaned with acetone, isopropanol and deionized water in an ultrasonic bath to remove possible contaminants from the surface. To achieve proper adhesion between the silicon wafer and the photoresist, 20\% hexamethyldisilazane (HMDS) (Sigma Aldrich, St. Louis, MO, USA) in xylene was spin-coated on the carefully cleaned and dried silicon wafers. Epoxy-based negative photoresist SU-8 2003 (MicroChem, Newton, MA, USA) was spun and pre-baked on the hot plate at $65^{\circ} \mathrm{C}$ for $1 \mathrm{~min}$ and at $95^{\circ} \mathrm{C}$ for $2 \mathrm{~min}$. After cooling, the SU-8 layer was exposed to 365-nm UV light (Karl Suss MA45, Suss Microtec Inc., Waterbury Center, VT, USA) through the photomask, and post-baked on the hot plate at $65^{\circ} \mathrm{C}$ for $1 \mathrm{~min}$ and at $95^{\circ} \mathrm{C}$ for $2 \mathrm{~min}$. Unexposed SU-8 areas were removed using propylene glycol mono-methyl ether acetate (PGMEA) immersion, and samples were cleaned in isopropanol and deionized water using an ultrasonication bath. A patterned SU-8 layer with a thickness of about $5 \mu \mathrm{m}$ resulted. Just before deposition of thin films, samples were post-baked at $95^{\circ} \mathrm{C}$ for $20 \mathrm{~min}$.

\section{Plasma vapour deposition (PVD)}

Two plasma vapour deposition (PVD) methods were used. A filtered pulsed plasma arc discharge method was used to deposit DLC films on the patterned sample discs. The system operated at a frequency of 1-7 Hz. The high-energy plasma needed to produce the adhesion layer was accelerated using a capacitor $(\mathrm{C}=16.0 \mu \mathrm{F})$ voltage of $\mathrm{U}=$ $6000 \mathrm{~V}$. After deposition of the adhesion layer, the main 
portion of a 200-nm-thick coating was deposited with a low-energy deposition unit run at average voltage of 500 $\mathrm{V}$ for about $15 \mathrm{~min}$.

Magnetron sputtering (Stiletto Serie ST20, AJA International Inc., North Scituate, MA, USA) was used to deposit thin films of titanium onto the surfaces of the patterned sample discs. The gas pressure was typically maintained in the range of $3-4 \times 10^{-4}$ mbar. A negative 400-500 V target potential was applied to accelerate the positively charged ions to the target. Targets were of high purity $(\geq 99.6 \%)$ titanium (Goodfellow Metals, Huntingdon, UK). Deposition of a 200-nm-thick layer took about $5 \mathrm{~min}$.

After deposition, silicon wafers were immersed in an acetone (ultrasonic) or resist remover (mr-Rem 660, Micro Resist Technology GmbH, Berlin, Germany) bath until the resist were solved (2-5 hours). The biomaterial coating deposited on the top of resist was removed together with the dissolved resist, and the final micro-patterns were formed. Silicon wafers were cut with a custom-made device using a diamond knife to $10 \mathrm{~mm} \times 10 \mathrm{~mm}$ samples containing four different sample areas.

\section{Sterilization}

Samples were placed in 70\% ethanol in Petri dishes for 30 min, after which most of the ethanol was removed, followed by evaporation for $20 \mathrm{~min}$. The samples were then packed in sterile packs and sterilized using gamma irradiation with a total dose of $31.8 \mathrm{kGy}$. The irradiations were conducted at the VTT Technical Research Centre of Finland by using a Co-60 source (Gammacell 220, Atomic Energy of Canada Limited, Ottawa, Canada).

\section{Cell cultures}

Human primary osteogenic sarcoma SaOS-2 (ECACC $890500205)$ cells were cultured in 10-cm-diameter Petri dishes (Corning Inc., Corning, NY, USA) using McCoy's 5 A culture medium containing GlutaMAX ${ }^{\mathrm{TM}}$ (Gibco BRL/ Life Technologies Inc., Gaithersburg, MD, USA) and supplemented with $10 \% \mathrm{v} / \mathrm{v}$ foetal calf serum (FCS), 100 $\mathrm{IU} / \mathrm{ml}$ of penicillin and $100 \mu \mathrm{g} / \mathrm{ml}$ of streptomycin. Cells were grown to $80 \%$ confluence at $37^{\circ} \mathrm{C}$ in a humidified incubator with $5 \% \mathrm{CO}_{2}$ in air. At $80 \%$ confluence, the culture medium was carefully decanted and the cell monolayer was washed twice with $10 \mathrm{mM}$ phosphatebuffered, $140 \mathrm{mM}$ saline (PBS, pH 7.4). Cells were removed from plates by applying a $0.25 \%$ trypsin and ethylenediaminetetraacetic acid (EDTA) solution for 5 min at $37^{\circ} \mathrm{C}$. Cells were resuspended in culture medium and seeded onto the biomaterial surfaces at a density of $15-25 \times 10^{3} \mathrm{~cm}^{-2}$. Tissue culture (TC)-treated polystyrene 12-well microplates (Corning Inc.) were used in all experiments. Experiments were done with four replicate samples of each type, and four pictures of each sample were analysed.

\section{Scanning electron microscopy}

Samples were cultured for 48 or $120 \mathrm{~h}$ at $37^{\circ} \mathrm{C}$ in a humidified incubator in $5 \% \mathrm{CO}_{2}$ in air. After incubation, samples were transferred to new tissue culture plates, washed twice with PBS and fixed in $2.5 \%$ glutaraldehyde
(Sigma) in PBS overnight at $4^{\circ} \mathrm{C}$. Samples were rinsed in PBS and dehydrated in a graded ethanol series $(50 \%, 70 \%$, $90 \%, 94 \%$ and absolute ethanol). Dehydration was completed using a Bal-Tec CPD 030 critical point drying unit (BAL-TEC AG, Balzers, Liechtenstein). Samples were mounted on scanning electron microscopy stubs, coated with a ca. 60-nm-thick platinum layer with an Agar sputter device (AGAR, Stansted, England) and examined using a Zeiss DSM 962 scanning electron microscope (Carl Zeiss, Oberkochen, Germany) at an accelerating voltage of 10 $\mathrm{kV}$ (filament current was about $60 \mu \mathrm{A}$ ).

\section{Confocal laser scanning microscopy}

Samples were cultured for $48 \mathrm{~h}$ at $37^{\circ} \mathrm{C}$ in a humidified incubator in $5 \% \mathrm{CO}_{2}$ in air. Samples were rinsed twice in PBS and cells were fixed in 4\% paraformaldehyde in PBS for $10 \mathrm{~min}$, rinsed twice in PBS and permeabilized in a $0.1 \% \mathrm{v} / \mathrm{v}$ Triton X-100 solution for $10 \mathrm{~min}$. After blocking in normal goat serum ( $1: 30$ in $0.1 \%$ bovine serum albumin (BSA) in PBS) for $1 \mathrm{~h}$, cells were incubated in an antivinculin antibody solution (1:5 dilution in BSA-PBS) for $1 \mathrm{~h}$ (Lehto and Virtanen, 1985). Cells were rinsed three times in PBS before Alexa fluor 488-conjugated secondary antibody (1:400 in BSA-PBS; Molecular Probes, Eugene, OR, USA) was applied for $30 \mathrm{~min}$. To detect actin simultaneously, Alexa fluor 568-conjugated phalloidin (Invitrogen, Carlsbad, CA, USA) was added (final dilution 1:30). Samples were rinsed three times with PBS and cell nuclei were stained with TO-PRO-3 (1:1000 in $\left.\mathrm{dH}_{2} \mathrm{O}\right)$ for $10 \mathrm{~min}$. Samples were rinsed twice in PBS, once with $\mathrm{dH}_{2} \mathrm{O}$ and mounted on objective slides. Immunofluorescent samples were observed under the fluorescence imaging microscope Olympus AX70 (Olympus, Tokyo, Japan) coupled with a CCD camera under 200-400x magnification. Stained cells were also observed in more detail using a Leica TCS SP2 confocal laser scanning microscope (Leica Microsystems GmbH, Mannheim, Germany) with an HCX PL APO CS 63/1.40 objective, and 488-, 568- and 633-nm laser excitation lines for Alexa Fluor 488-conjugate, Alexa Fluor 568-conjugate and the DNA-specific TO-PRO-3 probe, respectively. Image stacks were acquired using sequential scanning, a standardized 160-nm z-sampling density and a volume depth of $3.0 \mu \mathrm{m}$.

\section{Data analysis}

Cells were classified as being attached either on the interface $(<70 \%$ of the cell being on the pattern or alternatively on the background), on the pattern or on the background. Cells were counted by marking each group of cells with a different colour and counting the marks using a Matlab script. Coverage was analysed from each image by selecting an area of $0.490 \mathrm{~mm}^{2}$ containing 0.097 $\mathrm{mm}^{2}$ of patterned material.

The coverage was calculated semi-automatically in Matlab (The MathWorks Inc., Natick, MA, USA). The cells and patterned material squares could be separated from the uncovered background by finding their edges with a Canny edge detection operator (Canny, 1986). The areas inside the edges represent either a cell or a part of a material square. Objects smaller than 250 pixels $(<230$ 

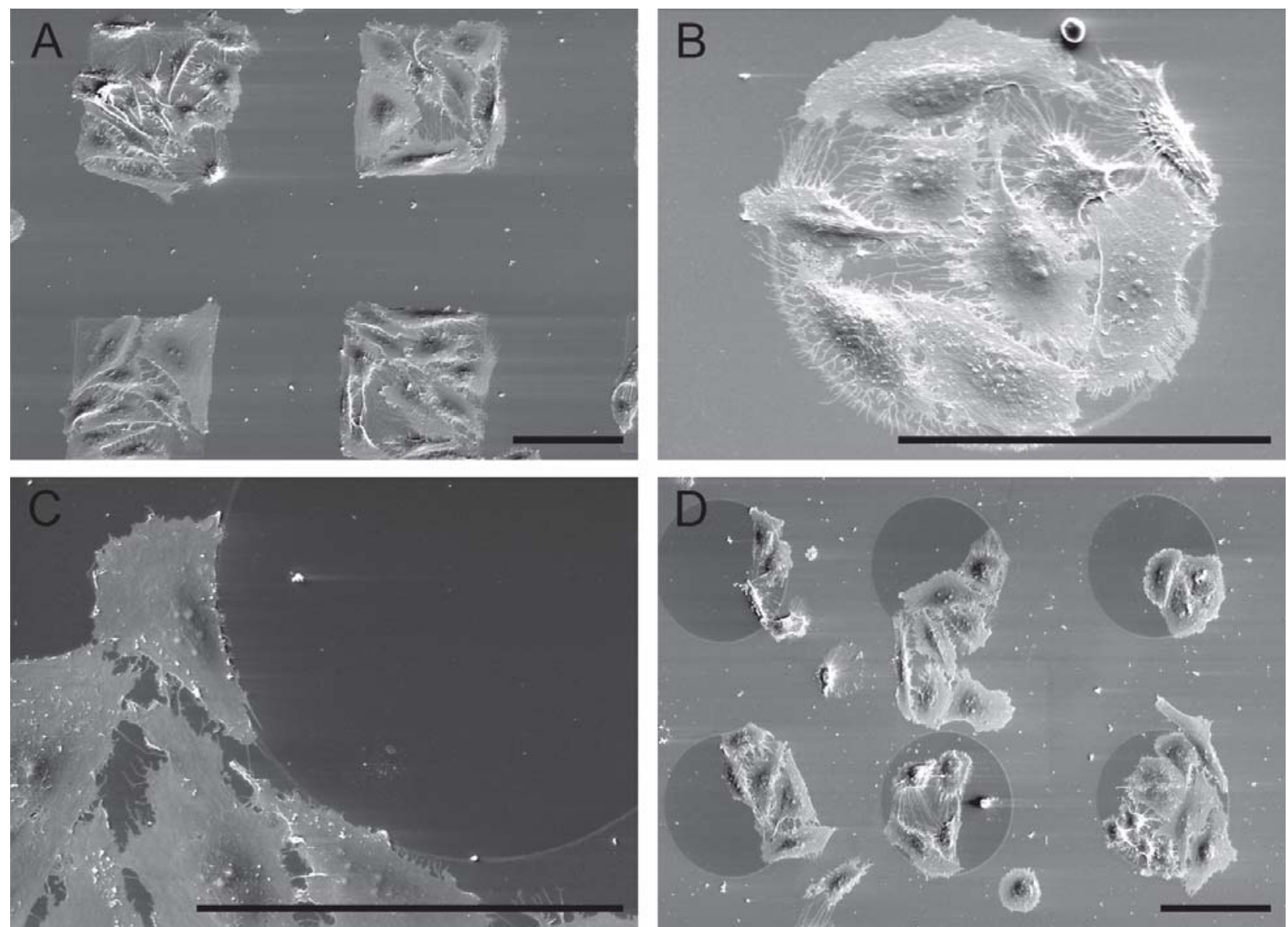

Fig. 2. Scanning electron microscopy disclosed that SaOS-2 cells at 48 hours adhered and spread well on large rectangular (panel A) or circular (panel B) titanium patterns, and in the inverse samples containing silicon islands on the titanium background (panel C), aligning themselves along the edges of the cell-friendly material. The cytocompatibility-enhancing and cell-guiding influence of DLC was weaker (panel D) than that of titanium. Scale bar is $100 \mu \mathrm{m}$.

$\mu \mathrm{m}^{2}$ ) were considered to be uncovered background and were removed from the image. Now, the uncovered background was segmented. In the next phase, uncovered material squares and cells were segmented manually by marking the edges (created by the Canny operator) on the image that contained object pixels (a cell or a material square) and background and comparing this image with the original image, and uncovered material squares were separated from cells manually. Some images needed extra manual segmentation since the Canny edge detector failed to detect all of the edges correctly; for example, in DLC samples, the material squares were not always detected. The accuracy of the method was not $100 \%$, but the errors were systematic, meaning that different samples could be compared against each other.

Relative cell density was obtained by dividing the number of cells by the area, coverage by dividing the area covered by the cells with the total area and the average cell size by dividing the covered area of the patterns or background by the number of the cells on the patterns or background, respectively.

One-way ANOVA (Matlab) followed by Tukey HSD Post-Hoc Tests was applied to determine the statistical significance of the differences observed between groups. All numerical results are expressed as mean \pm the standard deviation of the mean.

\section{Results}

\section{Qualitative effects of patterned silicon on cell adhesion and morphology after 48 hours}

For these experiments, DLC and titanium on silicon substrates were used (Fig. 2). In the short-term 48-h experiments, SaOS-2 cells adhered and spread well on the large rectangular (sides $125 \mu \mathrm{m}$ ) or circular (diameter 125 $\mu \mathrm{m})$ titanium patterns, which facilitated the adhesion of several cells. The shape of the pattern clearly controlled the adherence and spreading of the cells, both on the more crowded biomaterial islands on a silicon background (Fig. 2, panels A and B) and on the less crowded metallic background on inverse samples containing silicon islands (Figure 2, panel C). On patterned materials cells were large and well spread and the boundaries of the outermost cells followed the shape of the margins of the patterns to which they had attached (Fig. 2, panels A and B). On the inverse samples, composed of silicon islands on a titanium or DLC background, inverse behaviour was seen, with most cells now attaching to the background, but again following the edges of the patterns, aligning along them (Fig. 2, panel C). The cytocompatibility-enhancing and cell-guiding effects of DLC were clearly weaker (Fig. 2, panel D) than those of titanium (Fig. 2, panel A).

This preference of cells for biomaterial patterns over a 

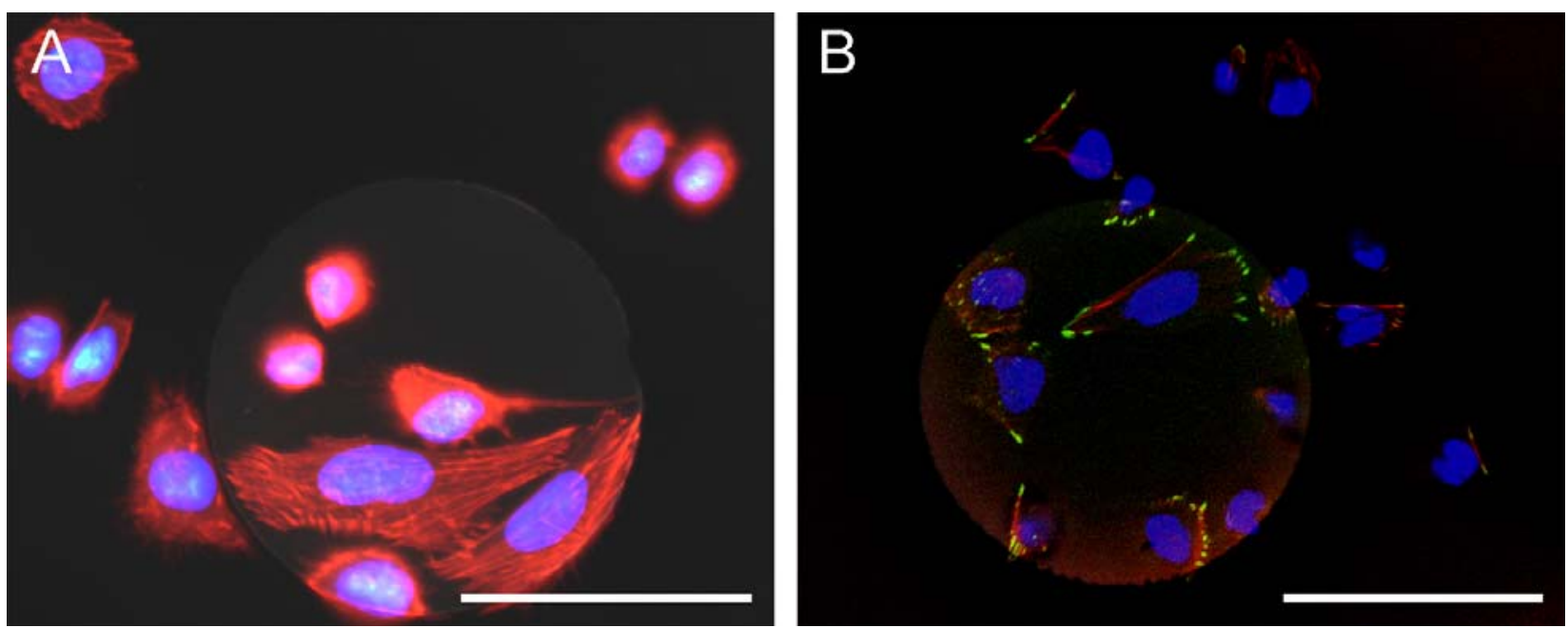

Fig. 3. Immunofluorescence staining of actin (in red) in SaOS-2 cells (blue nuclei) shows initial organization of actin cytoskeleton (panel A). Triple staining analysed in confocal laser scanning microscopy disclosed that this organization of the actin cytoskeleton (in red) in cells (blue nuclei) lying on biomaterial islands was probably due to formation of vinculin (in green) -containing adhesion plaques (panel B). Scale bar is $50 \mu \mathrm{m}$.

silicon background was confirmed by immunofluorescence staining of the actin cytoskeleton, which was well organized in cells on the biomaterial islands, but poorly organized in cells adhering to the silicon background (Fig. 3, panel A). Triple staining analysed by confocal laser scanning disclosed that this organization of the actin cytoskeleton in cells lying on biomaterial islands was probably the result of formation of vinculin-containing adhesion plaques, which were predominant in cells on biomaterial patterns, but reduced in cells lying on the silicon background (Fig. 3, panel B).

The total area of the medium-sized square $(25 \mu \mathrm{m})$ or circular $(25 \mu \mathrm{m})$ patterns was less than the mean area of an individual cell and designed so that singular cells could inhabit individual islands. Under these circumstances, the shape of the adhered cells no longer conformed strictly to the shape of the underlying silicon-covered coating (Fig. 4, panel A). Each cell usually covered only one pattern, although these cells, when on adjacent biomaterial islands, now tended to be in partial contact with each other (Fig. 4, panel B). A few cells covered two patterns, stretching from one pattern to another (inter-island distance of $15 \mu \mathrm{m}$ ), giving these cells elongated shapes (Fig. 4, panel C). Cells occasionally inhabited three or more islands, leading to branched or star-like cell shapes (not shown). On the inverse samples cells attached to the background, but these cells were usually relatively few and had an elongated or slightly rounded appearance when they passed through the narrow passages between the patterns, e.g. only $15 \mu \mathrm{m}$ between the circular patterns (Fig. 4, panel D). Some cells on these samples did not attach or had detached and displayed a rounded cell morphology (not shown). The effects of medium-sized DLC patterns were fairly similar to those of patterns composed of titanium such that cells preferred or even competed for the DLC patterns at the cost of the silicon background (Fig. 4, panel E).

In their adherence and spreading on sample areas containing small-sized square $(5 \mu \mathrm{m})$ or circular $(5 \mu \mathrm{m})$ DLC or titanium patterns, cells again showed a preference for these coating materials over silicon, independent of whether these materials were located on the patterns or on the background (inverse samples). However, this was displayed in a different (third) way. Individual patterns were too small to accommodate a single cell so the cells seemingly non-selectively stretched over larger areas covering several DLC titanium, or (in inverse samples) silicon islands and the intervening background (Fig. 5, panel A). However, at their outer edges, cells sent thin and slender filopodia, which seemed to prefer the more cellfriendly material, trying to circumvent and avoid bare silicon-coated areas (Fig. 5, panel A).

\section{Qualitative effects of patterned silicon on cell adhesion and morphology after 120 hours}

After 120 hours in culture cells formed seemingly continuous monolayers on almost all samples containing DLC or titanium patterns on silicon substrate (Fig. 6, panel A). There were two exceptions. Firstly the disruptive effect of silicon on cell adhesion was still evident in large patterns on titanium samples (Fig. 6, panel B). The second exception was that almost all cells had detached from the sample areas containing a homogeneous (non-patterned) DLC surface (Fig. 6, panel C).

\section{Quantitative effect of pattern material on cell behaviour after 48 hours}

Samples containing $75-\mu \mathrm{m}$ squares of DLC or titanium on silicon substrate were used. The relative cell density at $48 \mathrm{~h}$ was 3.4-3.7 times higher on both coating materials than on the silicon substrate ( $p<0.000000001$, Fig. 7).

Comparison of the different biomaterials used for coating silicon showed that the numbers of cells present at the patterned/nonpatterned interface were much lower in DLC samples than on titanium $(p<0.001)$.

The relative coverage was 2.0-2.8-fold higher for titanium and DLC than for the silicon substrate $(p<0.001$, Fig. 8). Comparison between the patterning materials disclosed that the proportions of area covered by cells were higher for titanium $(p<0.002)$ than for DLC. The silicon background on titanium samples was better covered than 

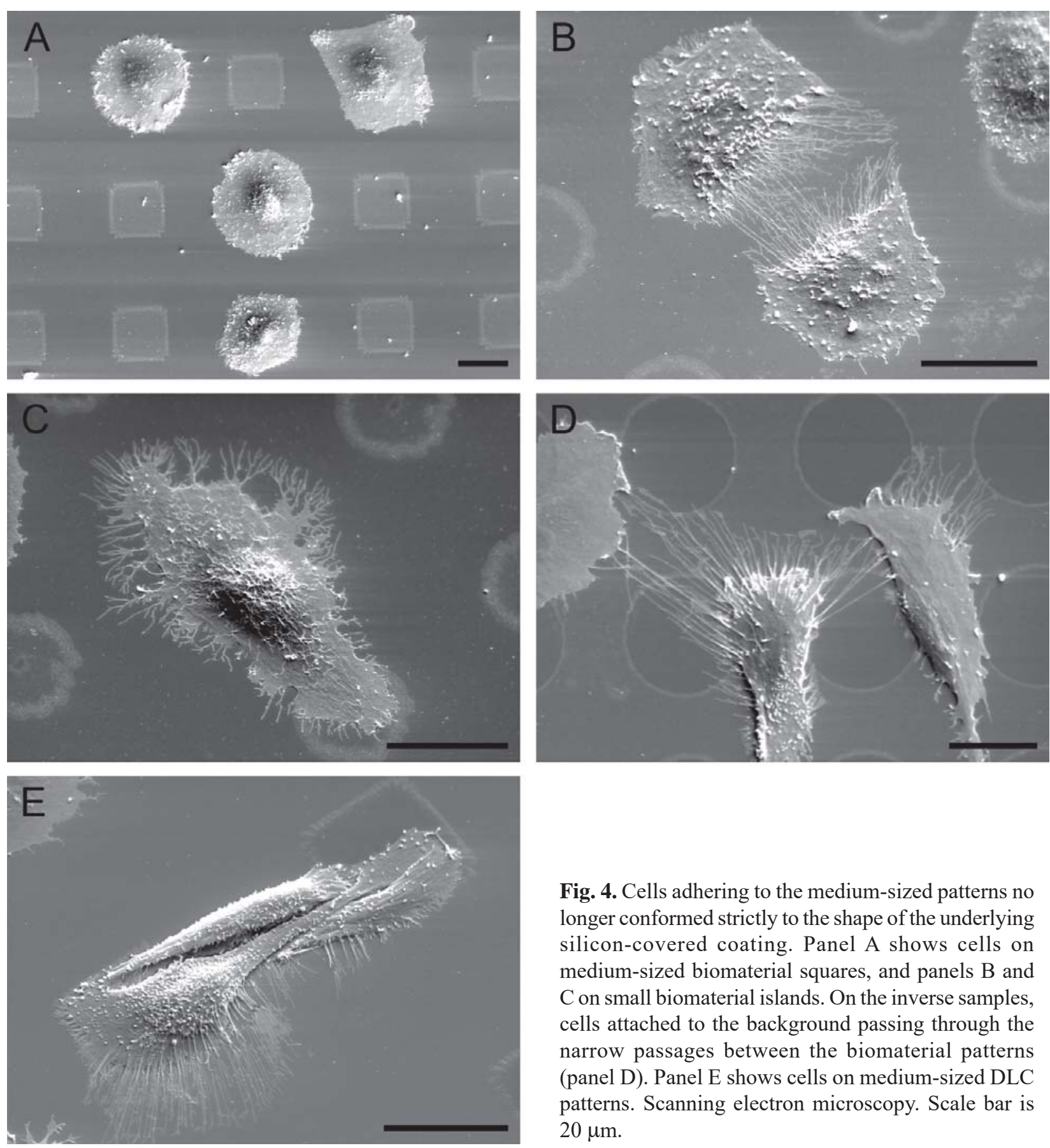

Fig. 4. Cells adhering to the medium-sized patterns no longer conformed strictly to the shape of the underlying silicon-covered coating. Panel A shows cells on medium-sized biomaterial squares, and panels B and $\mathrm{C}$ on small biomaterial islands. On the inverse samples, cells attached to the background passing through the narrow passages between the biomaterial patterns (panel D). Panel E shows cells on medium-sized DLC patterns. Scanning electron microscopy. Scale bar is $20 \mu \mathrm{m}$.

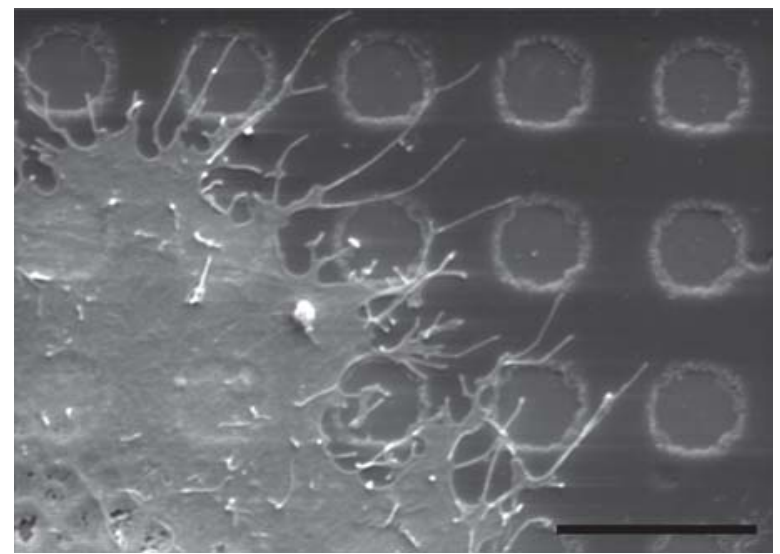

Fig. 5. Cells on the small-sized patterns simultaneously covered numerous patterns and intervening background, shown in this micrograph for an inverse diamond-like carbon (DLC) silicon sample. Despite of this seemingly nonselective adherence to the sample surface area, filopodia clearly demonstrated a cellular preference for DLC over silicon. Scanning electron microscopy. Scale bar is $10 \mu \mathrm{m}$. 

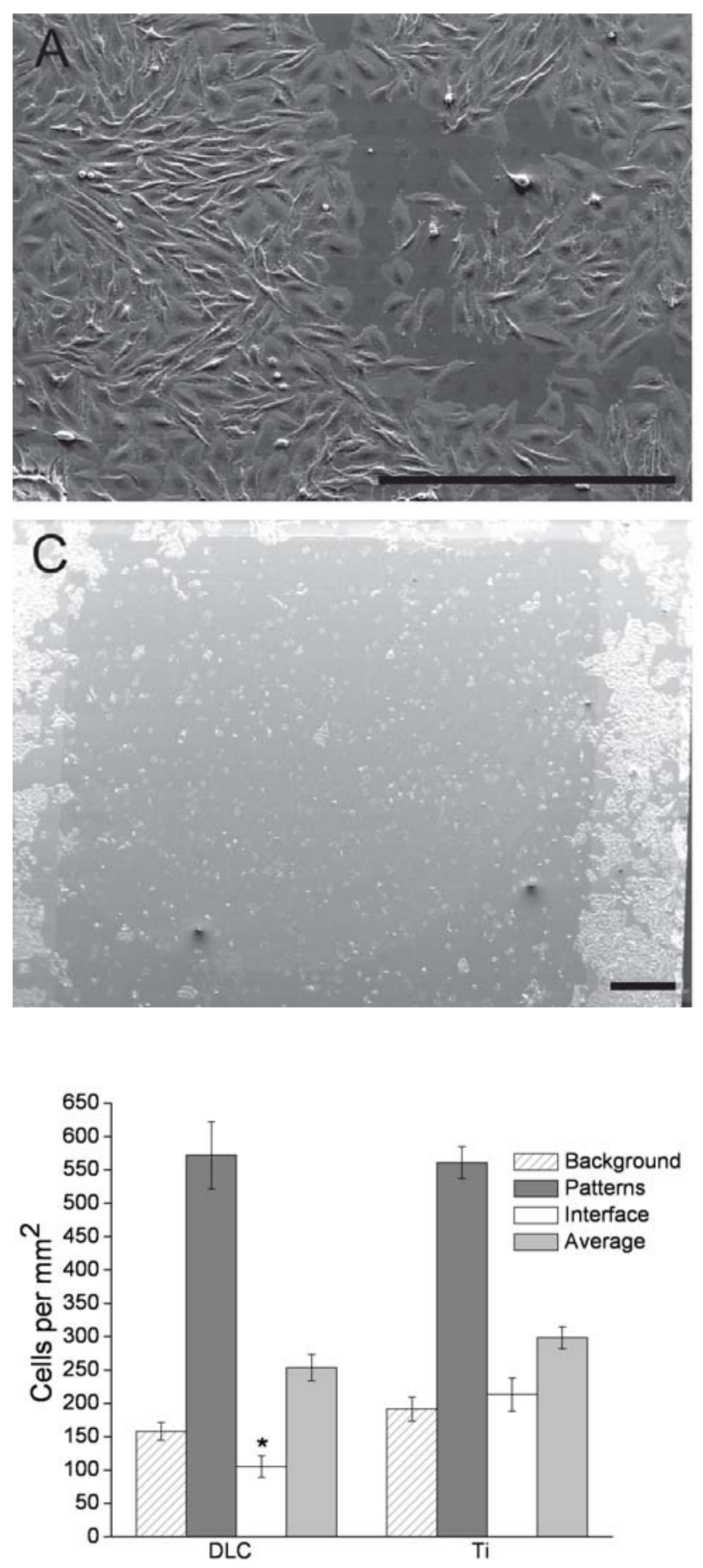

Fig. 7. Density of SaOS-2 cells was always higher on diamond-like carbon (DLC) and titanium patterns (islands) than on the silicon background $(p<0.000000001)$. Statistically significantly lower adherence to the interface in DLC-containing samples than in the interfaces in titanium is denoted with a star $(*$, for exact $p$-values, see text).

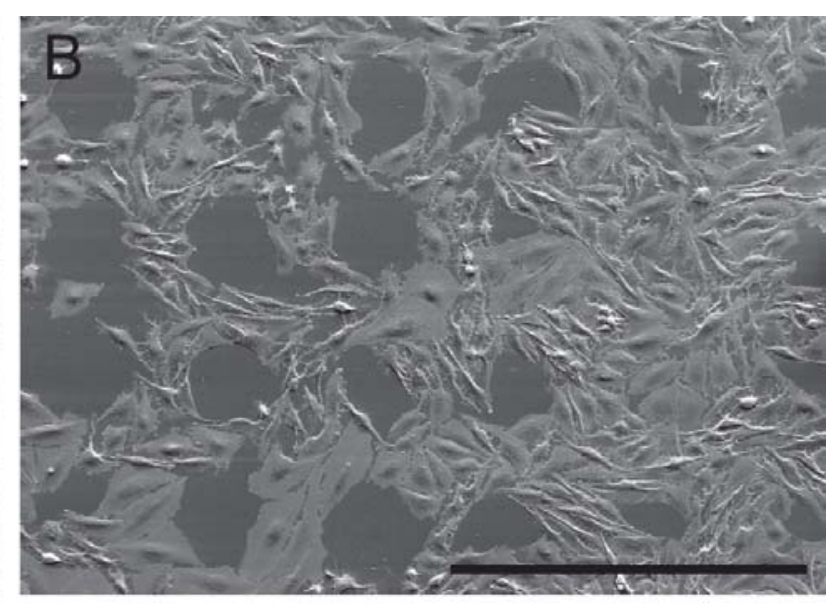

Fig. 6. In the $120 \mathrm{~h}$ experiments, SaOS-2 cells formed almost continuous monolayers (panel A, the area selected so that the medium-sized patterns can be seen on the background). However, some cell guidance was still seen in large-pattern, titanium-containing samples (panel B, inverse sample), whereas almost all cells had detached from the sample areas containing a homogeneous (non-patterned) DLC surface (panel C, low magnification, the large and homogeneous $4 \mathrm{~mm}$ $\mathrm{x} 4 \mathrm{~mm}$ DLC square is surrounded by other sample areas containing micro-textured DLC, where cells form almost continuous monolayers). Scale bar is $500 \mu \mathrm{m}$.

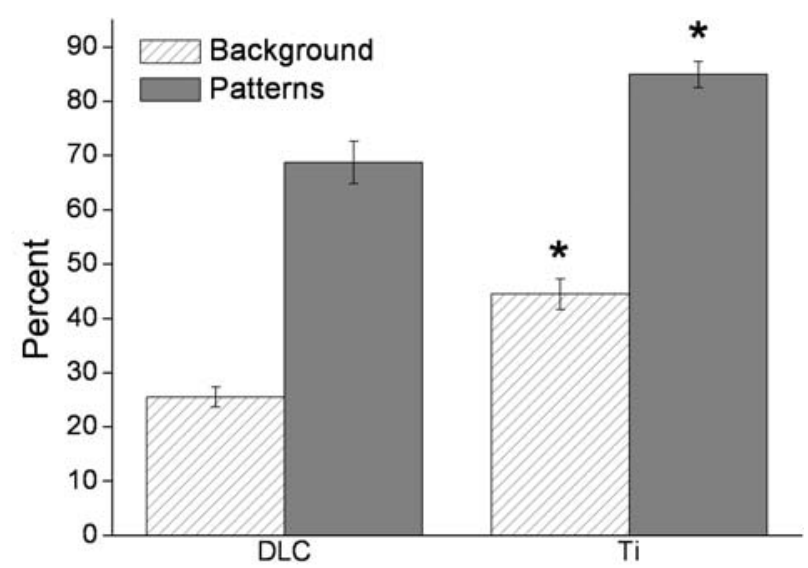

Fig. 8. Coverage of SaOS-2 cells was always higher on diamond-like carbon (DLC) and titanium patterns (islands) than on the silicon background $(p<0.000000001)$. Some differences existed between the biomaterials used for patterning of the silicon background; titanium was better covered than DLC, and silicon background on titanium-patterned samples was better covered than the background on DLC samples $(*$, for exact $p$-values, see text). 


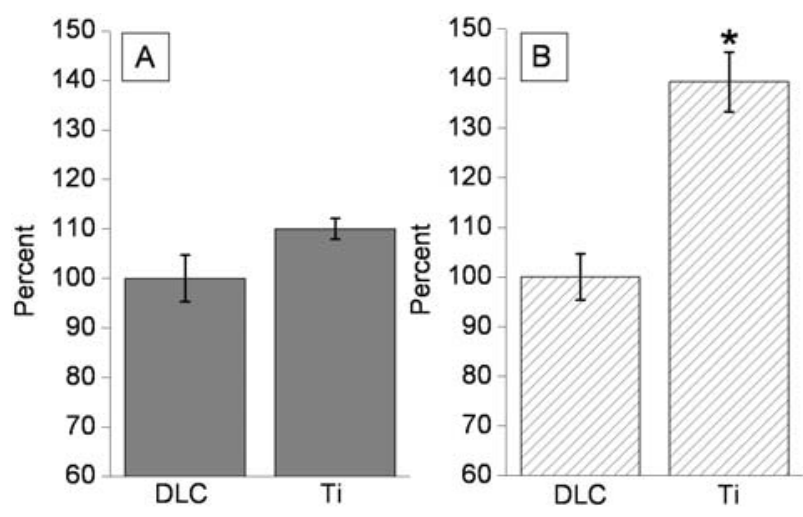

Fig. 9. Relative size of SaOS-2 cells on biomaterial patterns (panel A) and silicon background (panel B) normalized for the smallest samples $(100 \%$ for diamond). Cell size was marginally larger on titanium $(* p<0.06)$ than on diamond-like carbon (DLC) (panel A). Cell size was larger on the silicon background of titanium-patterned samples than on the background of DLC samples ( $* p<0.00001)$.

the background on DLC-patterned samples. The highest pattern-to-background ratio was recorded for DLC, which differed from titanium $(p<0.0002)$.

The average sizes of the cells varied greatly between biomaterial-patterns (Fig. 9, panel A) and silicon backgrounds (Fig. 9, panel B). On titanium-patterned samples, the cells were also significantly larger on the silicon background than on the backgrounds containing DLC-patterns $(p<0.00001$, Fig. 9), although the background material and the preparation methods of all patterns and backgrounds were the same for all samples. The sizes of the cells on the silicon background of titanium samples were over $40 \%$ larger than on the background of DLC samples (Fig. 9).

\section{Discussion}

Silicon is easily grown as oxides and has semi-conductor properties and superb semi-conductor/dielectric interface and therefore widely used in microchips. Compared to bioactive glass, silicon dioxides are quite tissue-unfriendly (Hench and Wilson, 1986; Liu et al., 2004), inhibiting their use in devices designed to be integrated with the human body. It was hypothesized that cytocompatibility of the silicon-based materials could be enhanced by only partial surface micro-texturing with well-known biocompatible materials: cell adhesion and spreading of the cells were improved $(p<0.001$ for both biomaterial vs. silicon comparisons). The presence of a silicon surface did not impair the attachment of the cells to biomaterial islands, which were surrounded a perturbing silicon-oxide background.

The shape and size of the patterns influenced adhesion and spreading of human cells. There was a clear cellular preference for the micro-textured surfaces over background silicon. Cells initially adopted the geometrical architecture of the islands assuming either square or circle shapes. Analysis of vinculin-positive adhesion plaques and organization of the actin cytoskeleton revealed that silicon substrates inhibited cell adhesion, whereas cells on the biomaterial islands showed signs of active attachment, preferentially adhering to the pattern periphery which provides the cells with useful physical cues for the formation of focal adhesions.

The size and spacing of the patterns offered further options to control and guide integration of micro-textured chips and human cells. Three-fold evidence was obtained, based on the use of three different sized patterns. Cells clearly preferred attachment to $250 \mu \mathrm{m}$ wide patterns and aligned according to their contours. The medium-sized biomaterial islands were sufficiently small that the cell had to adapt itself to a smaller size to be able to remain on the biocompatible pattern. Because the percentage area of the silicon chip covered by the patterns was kept constant, these medium-sized patterns were relatively close to each other, e.g. circles were spaced only $15 \mu \mathrm{m}$ apart. This led to two different, distinct phenomena. Cells inhabiting neighbouring islands extended over the intervening background and seemed to be trying to establish direct cell-to-cell contacts (Civitelli et al., 1993). In addition, one cell could occupy two or more biomaterial islands, leading to the formation of elongated, branching or stellate morphologies.

Finally, the preference of the cells for the enhancing biomaterials was also observed in the small-sized patterns, too small to be inhabited by a singular cell. Now the cell body covered several small patterns, but at its advancing edge it extended numerous slender filopodia, which seemed to be exploring the surrounding substrate. These filopodia clearly preferred the cell-friendly, cytocompatibility-enhancing biomaterials and bypassed and circumvented surfaces where the background silicon substrate was exposed. These descriptive observations seen in SEM, IF and CLSM images were confirmed by morphometric calculations subjected to statistical testing, which quantitatively and statistically confirmed the qualitative cytological observations.

After the initial, above-described successful adhesion phase of the cells to selected cell-friendly integration spots, cells at $120 \mathrm{~h}$ had further spread to previously uninhabited silicon-based background to form confluent cellular monolayers. This suggests that already partial coating of bioMEMS devices can be used to enhance their cytocompatibility and to facilitate their integration with the host during the critical initial integration phase. Such integration may in part be facilitated by soluble factors and direct cell-to-cell contacts. This was suggested by the consequent and highly significant differences in the coverage and size of the cells growing on the silicon background in samples containing islands composed of different biomaterials. For example, both the coverage and the size of the cells on the background were higher in samples containing titanium than DLC. A second potential advantage of this rapid initial integration of host cells is related to the risk of implant-related infections, a risk always associated with the human use of such devices. Swift coverage of the vulnerable abiotic device surface would, according to the "race for the surface" concept 
(Gristina, 1987; Subbiahdoss et al., 2009), protect against implant-related infections.

This study deals with silicon surfaces, which contain metal or DLC patterns. These material combinations have not been evaluated before, but similar studies have been done using other types of patterns. Cells tend to align along grooves (Brunette et al., 1983; Chou et al., 1995; Britland et al., 1996; Curtis and Wilkinson, 1997; Chou et al., 1998; Teixeira et al., 2003; Dalby et al., 2004; Ber et al., 2005; Mwenifumbo et al., 2007; Loesberg et al., 2007) and the cell shape is affected by the surface topography of the substrate (Ingber, 1990; Singhvi et al., 1994; den Braber et al., 1996; Bigerelle et al., 2002).

The only published study thus far focusing on silicon surfaces patterned with DLC concluded that patterned deposition of different kinds of diamonds (DLC, oxidized DLC or phosphorous-doped DLC) can be used to generate spatially directed neurone growth (Kelly et al., 2008).

In a previous study of ours on human mesenchymal stem cells (Myllymaa et al.,2010) cultured on similarly patterned samples (Fig. $1 \mathrm{C}$ ), we found that these cells preferred the biomaterial patterns over the silicon background. Moreover, mesenchymal stem cells, similar to SaOS-2 cells, were smaller on biomaterial islands than on the silicon background. In the present study we observed that the size of the cells growing on the same silicon background varied significantly depending on the type of biomaterial used for patterning.

\section{Conclusion}

The initial working hypothesis was proven. Even partially patterned DLC and titanium coating enhanced the cytocompatibility of bioMEMS dummies. In addition to the chemical composition of the materials used for surface modification, this enhancement is also dependent on the shape, edges (height) and size of the patterns used for micro-texturing, which can be used to enhance biocompatibility during the initial integration phase of the device.

\section{Acknowledgements}

This study was financially supported by TEKES "Micro robotic diagnostics and therapy", the Danish Council for Strategic Research "Individualized musculoskeletal regeneration and reconstruction network", the European Science Foundation "Regenerative medicine" RNP, COST Action 533 "Biotribology", ENT ERA Net "A new generation of titanium biomaterials", the Sigrid Jusélius Foundation, Evo grants, Helsinki University Central Hospital, Finland Läkaresällskapet and ORTON Orthopaedic Hospital of the Invalid Foundation. Support for the study was also obtained from the National PhD Graduate School in Musculoskeletal Diseases and Biomaterials. We thank the Electron Microscopy Unit of the Institute of Biotechnology-University of Helsinki and the Microsensor Laboratory of the Savonia University of Applied Sciences for providing laboratory facilities. We also thank Hannu Korhonen for his contribution to sample fabrication.

\section{References}

Ber S, Torun Köse G, Hasirci V (2005) Bone tissue engineering on patterned collagen films: an in vitro study. Biomaterials 26: 1977-1986.

Berry CC, Curtis ASG, Oreffo ROC, Agheli H, Sutherland DS (2007) Human fibroblast and human bone marrow cell response to lithographically nanopatterned adhesive domains on protein rejecting substrates. IEEE Trans Nanobioscience 6: 201-209.

Bigerelle M, Anselme K, Noël B, Ruderman I, Hardouin P, Iost A (2002) Improvement in the morphology of Ti-based surfaces: a new process to increase in vitro human osteoblast response. Biomaterials 23: 1563-1577.

Biggs MJP, Richards RG, Gadegaard N, Wilkinson CDW, Dalby MJ (2007a) Regulation of implant surface cell adhesion: characterization and quantification of Sphase primary osteoblast adhesions on biomimetic nanoscale substrates. J Orthop Res 25: 273-282.

Biggs MJP, Richards RG, Gadegaard N, Wilkinson CDW, Dalby MJ (2007b) The effects of nanoscale pits on primary human osteoblast adhesion formation and cellular spreading. J Mater Sci Mater Med 18: 399-404.

Boyan BD, Hummert TW, Dean DD, Schwartz Z (1996) Role of material surfaces in regulating bone and cartilage cell response. Biomaterials 17: 137-146.

Britland S, Morgan H, Wojiak-Stodart B, Riehle M, Curtis A, Wilkinson C (1996) Synergistic and hierarchical adhesive and topographic guidance of BHK cells. Exp Cell Res 228: 313-325.

Brunette DM, Kenner GS, Gould TRL (1983) Grooved titanium surfaces orient growth and migration of cells from human gingival explants. J Dent Res 62: 1045-1048.

Canny J (1986) A computational approach to edge detection. IEEE TPAMI 8: 679-698.

Chen CS, Mrksich M, Huang S, Whitesides GM, Ingber DE (1997) Geometric control of cell life and death. Science 276: $1425-1428$.

Chou L, Firth JD, Uitto VJ, Brunette DM (1995) Substratum surface topography alters cell shape and regulates fibronectin mRNA level, mRNA stability, secretion and assembly in human fibroblasts. J Cell Sci 108: $1563-1573$.

Chou L, Firth JD, Uitto VJ, Brunette DM (1998) Effects of titanium substratum and grooved surface topography on metalloproteinase-2 expression in human fibroblasts. J Biomed Mater Res 39: 437-445.

Civitelli R, Beyer EC, Warlow PM, Robertson AJ, Geist ST, Steinberg TH (1993) Connexin43 mediates direct intercellular communication in human osteoblastic cell networks. J Clin Invest 91: 1888-1896.

Curtis A, Wilkinson C (1997) Topographical control of cells. Biomaterials 18:1573-1583.

Dalby MJ, Riehle MO, Sutherland DS, Aghelib H, Curtis ASG (2004) Use of nanotopography to study mechanotransduction in fibroblasts - methods and perspectives. Eur J Cell Biol 83: 159-169.

den Braber ET, de Ruijter JE, Ginsel LA, von Recum AF, Jansen JA (1996) Quantitative analysis of fibroblast morphology on microgrooved surfaces with various groove and ridge dimensions. Biomaterials 17: 2037-2044. 
Falconnet D, Csucs G, Grandin HM, Textor M (2006) Surface engineering approaches to micropattern surfaces for cell-based assays. Biomaterials 27: 3044-3063.

Flemming RG, Murphy CJ, Abrams GA, Goodman SL, Nealey PF (1999) Effects of synthetic micro- and nanostructured surfaces on cell behavior. Biomaterials 20: 573588 .

Grayson ACR, Shawgo RS, Johnson AM, Flynn NT, LI Y, Cima MJ, Langer R (2004) A BioMEMS review: MEMS technology for physiologically integrated devices. IEEE J PROC 92: 6-21.

Gristina AG (1987) Biomaterial-centered infection: microbial adhesion versus tissue integration. Science 237: 1588-1595.

Hanein Y, Pan YV, Ratner BD, Denton DD (2001) Micromachining of nonfouling coatings for bio-MEMS applications. Sens Actuators B Chem 81: 49-54.

Hart A, Gadegaard N, Wilkinson CDW, Oreffo ROC, Dalby MJ (2007) Osteoprogenitor response to lowadhesion nanotopographies originally fabricated by electron beam lithography. J Mater Sci Mater Med 18: 1211-1218.

Healy KE, Thomas CH, Rezania A, Kim JE, McKeown PJ, Lom B, Hockberger PE (1996) Kinetics of bone cell organization and mineralization on materials with patterned surface chemistry. Biomaterials 17:195-208.

Hench LL, Wilson J (1986) Biocompatibility of silicates for medical use. Ciba Found Symp 121: 231-246.

Ingber DE (1990) Fibronectin controls capillary endothelial cell growth by modulating cell shape. Proc Nat Acad Sci 87: 3579-3583.

Kelly S, Regan EM, Uney JB, Dick AD, McGeehan JP, Group BB, Mayer EJ, Claeyssens F (2008) Patterned growth of neuronal cells on modified diamond-like carbon substrates. Biomaterials 29: 2573-2580.

Keselowsky BG, Collard DM, Garca AJ (2003) Surface chemistry modulates fibronectin conformation and directs integrin binding and specificity to control cell adhesion. J Biomed Mater Res A 66: 247-259.

Kunzler TP, Huwiler C, Drobek T, Vrs J, Spencer ND (2007) Systematic study of osteoblast response to nanotopography by means of nanoparticledensity gradients. Biomaterials 28: 5000-5006.

Lan S, Veiseh M, Zhang M (2005) Surface modification of silicon and goldpatterned silicon surfaces for improved biocompatibility and cell patterning selectivity. Biosens Bioelectron 20: 1697-1708.

Lappalainen R, Anttila A, Heinonen H (1998) Diamond coated total hip replacements. Clin Orthop Relat Res 352: 118-127.

Lehto V-P, Virtanen I (1985) Vinculin in cultured bovine lens-forming cells. Cell Differ 16:153-160.

Liu X, Fu RKY, Poon RWY, Chen P, Chu PK, Ding C (2004) Biomimetic growth of apatite on hydrogenimplanted silicon. Biomaterials 25: 5575-5581.

Loesberg WA, te Riet J, van Delft FCMJM, Schön P, Figdor CG, Speller S, van Loon JJWA, Walboomers XF, Jansen JA (2007) The threshold at which substrate nanogroove dimensions may influence fibroblast alignment and adhesion. Biomaterials 28: 3944-3951.
Myllymaa A, Kaivosoja E, Myllymaa K, Sillat T, Korhonen H, Lappalainen R, Konttinen YT (2010) Adhesion, spreading and osteogenic differentiation of mesenchymal stem cells cultured on micropatterned amorphous diamond, titanium, tantalum and chromium coatings on silicon. J Mater Sci Mater Med 21: 329-341.

Mwenifumbo S, Li M, Chen J, Beye A, Soboyejo W (2007) Cell/surface interactions on laser micro-textured titanium-coated silicon surfaces. J Mater Sci Mater Med 18: 9-23.

Owen GR, Jackson J, Chehroudi B, Burt H, Brunette DM (2005) A PLGA membrane controlling cell behaviour for promoting tissue regeneration. Biomaterials 26: 74477456.

Santavirta S, Takagi M, Gmez-Barrena E, Nevalainen J, Lassus J, Salo J, Konttinen YT (1999) Studies of host response to orthopedic implants and biomaterials. J Long Term Eff Med Implants 9: 67-76.

Singhvi R, Kumar A, Lopez GP, Stephanopoulos GN, Wang DC, Whitesides GM, Ingber E (1994) Engineering cell shape and function. Science 264: 696-698.

Subbiahdoss G, Kuijer R, Grijpma DW, van der Mei HC, Busscher HJ (2009) Microbial biofilm growth vs. tissue integration: "the race for the surface" experimentally studied. Acta Biomater 5: 1399-1404.

Teixeira AI, Abrams GA, Bertics PJ, Murphy CJ, Nealey PF (2003) Epithelial contact guidance on welldefined micro- and nanostructured substrates. J Cell Sci 116: $1881-1892$.

Thomas CH, Collier JH, Sfeir CS, Healy KE (2002) Engineering gene expression and protein synthesis by modulation of nuclear shape. Proc Natl Acad Sci U S A 99: 1972-1977.

van Kooten TG, Whitesides JF, von Recum A (1998) Influence of silicone (PDMS) surface texture on human skin fibroblast proliferation as determined by cell cycle analysis. J Biomed Mater Res 43: 1-14.

Veiseh M, Wickes BT, Castner DG, Zhang M (2004) Guided cell patterning on gold-silicon dioxide substrates by surface molecular engineering. Biomaterials 25: 33153324.

Voskerician G, Shive MS, Shawgo RS, von Recum H, Anderson JM, Cima MJ, Langer R (2003) Biocompatibility and biofouling of MEMS drug delivery devices. Biomaterials 24: 1959-1967.

\section{Discussion with Reviewers}

Reviewer I: The authors state that cells cultured on silicon exhibited an unknown intersample variation in cell size; do they think this may be a result of cell cycle induced changes in morphology?

Authors: This refers to "The size of the cells on the silicon background of titanium samples was over $40 \%$ larger than on the background of DLC samples (Fig. 9)." This was considered as an interesting observation. Cell cycles are hardly synchronized in this type of experiment. Our interpretation of this observation is that the cells on titanium patterns produce some soluble stimuli, such as trophic 
stimuli and/or growth factors, which exert distance paracrine effects on the cells adherent to the silicon background. Apparently, cells growing on DLC produce much less such factors so the cells on silicon background were $29 \%$ smaller than they were on silicon background on samples containing titanium patterns.

Alternatively, it could be hypothesized that cells growing on DLC produce some cytostatic factors, which inhibit growth and/or spreading of the distant cells growing on the silicon background. This is supported by the current observation that cells cultured on homogeneous DLC surfaces had at day 6 apparently detached from the substrate, probably as a result of anoikis, a form of apoptosis following loss of cell-to-matrix contact. By contrast, titanium, which is in general considered a cytocompatible, cell-friendly material, would be less likely to produce such cell-hostile soluble factors.

Reviewer I: Due to the nature of substrate fabrication, it would seem unlikely that individual patterned areas would possess notable topographical at the micron or nanoscale. Regarding similar pattern conformations of different materials, do the authors attribute the differences observed in the cellular response to be purely due to surface chemistry?

Authors: Topographical and physical cues of the substrate at the micron and nanoscale can in fact affect cellular responses. In a separate piece of work on micro-texture and mesenchymal stromal/stem cells (Myllymaa et al., 2010 , text reference), we used the same production technology combining photolithography and physical vapour deposition. Surface roughness was measured using atomic force microscopy. This disclosed that the average surface roughness $\mathrm{R}_{\mathrm{a}}$ was below $2 \mathrm{~nm}$ for all studied surfaces in that and probably in the current set of samples. The smallest features cellular filopodia, which are considered to have a sensory role, can sense are ca. 5-10 $\mathrm{nm}$ height differences (Curtis and Wilkinson, 2001; Dalby et al., 2004). Topographical cues $<2 \mathrm{~nm}$ play hardly a role here. It is therefore concluded that it is basically the chemical nature of the material which in this setting defines the behaviour of the cells, probably indirectly via interactions with electrolytes, protons, proteins and other constituents of the cell culture medium.

Reviewer II: Micro-texturing with biomaterials is shown to enhance the cytocompatibility of silicon-based microelectro-mechanical-system. Will this approach generate "side-effect" for example on the mechanical properties of the silicon rendering the use of the treated MEMS difficult for its supposed mechanical action?

Authors: In soft tissue, non-load-bearing applications, surface modification of silicon chips with metal or DLC has virtually no impact on the mechanical strength of the silicon chip or the device itself. BioMEMS devices are hardly suitable for heavy-duty, load-bearing applications, and under such circumstances also delamination and fracture of the surface coating would present a potential threat. Such limitations must be taken into consideration in the design of complex medical devices containing bioMEMS components.

As it makes sense from a "common sense" point of view that improved biocompatibility during the initial integration phase of an implant may be positive, from a more scientific point of view, is there any evidence supporting this fact for the long term implant integration?

An important point of view is the "race for the surface" concept (Gristina, 1987; Subbiahdoss et al., 2009, text references), according to which the surface is covered by tissue and less vulnerable to bacterial colonization, if the race is won by tissue cells. Secondly, if osseointegration is slow, too much fibrous tissue forms. This leads to a fixation of the prosthesis to fibrous tissue rather than to bone, which in turn leads to early loosening through continued micromotion of the prosthesis (Bobyn et al., 1987; Engh et al., 1987; Søballe et al., 1993; Hauptfleish et al., 2006).

\section{Additional References}

Bobyn JD, Engh CA, Glassman AH (1987) Histologic analysis of a retrieved microporous-coated femoral prosthesis. A seven-year case report. Clin Orthop Relat Res 224: 303-310.

Curtis A, Wilkinson C (2001) Nantotechniques and approaches in biotechnology. Trends Biotechnol 19: $97-$ 101.

Dalby MJ, Riehle MO, Johnstone H, Affrossman S, Curtis, ASG (2004) Investigating the limits of filopodial sensing: a brief report using SEM to image the interaction between $10 \mathrm{~nm}$ high nano-topography and fibroblast filopodia. Cell Biol Int 28: 229-236.

Engh CA, Bobyn JD, Glassman AH (1987) Porouscoated hip replacement. The factors governing bone ingrowth, stress shielding, and clinical results. J Bone Joint Surg Br 69: 45-55.

Hauptfleisch J, Glyn-Jones S, Beard DJ, Gill HS, Murray DW (2006) The premature failure of the Charnley Elite-Plus stem: a confirmation of RSA predictions. J Bone Joint Surg Br 88: 179-183.

Søballe K, Toksvig-Larsen S, Gelineck J, Fruensgaard S, Hansen ES, Ryd L, Lucht U, Brünger C (1993) Migration of hydroxyapatite coated femoral prostheses. A Roentgen Stereophotogrammetric study. J Bone Joint Surg Br 75: 681-687. 